\title{
Effect of Cathodic Potentials on the Hydrogen Embrittlement Susceptibility of 10Ni5CrMo Steel
}

\author{
Pengfei Yin ${ }^{1,2, *}$, Xiangyang Li ${ }^{1}$, Wenping Lu ${ }^{2}$, Yalin Chen ${ }^{2}$, Zhaohui Yang ${ }^{2}$, Bo Zhang ${ }^{2}$, \\ Yong Guo ${ }^{2}$, Jifeng Ding 2 , Rongkai Cao ${ }^{3}$ \\ ${ }^{1}$ Central Iron and Steel Research Institute, Beijing 100081, China \\ ${ }^{2}$ Qingdao NCS Testing and Protection Technology Co., Ltd, Qingdao 266071, China \\ ${ }^{3}$ College of Electromechanical Engineering, Qingdao University of Science and Technology, Qingdao \\ 266061 \\ *E-mail: ypf1201@163.com
}

doi: $10.20964 / 2019.09 .17$

Received: 11 April 2019 / Accepted: 14 June 2019 / Published: 31 July 2019

\begin{abstract}
The effects of the cathodic polarization potential on the hydrogen embrittlement susceptibility of 10Ni5CrMo steel in seawater were studied using a slow strain rate tensile test (SSRT) combined with observation of the fracture morphology and electrochemical measurements, as well as the hydrogen permeation test. The results showed that the rate controlling step of the cathode reaction changed from the oxygen depolarization reaction to the hydrogen depolarization reaction with the increase in the cathodic polarization level. With the negative shift in the polarization potential, the sample's reduction of area (R/A) and elongation decreased, and the fracture surfaces of the specimens displayed a transition from ductile microvoid coalescence to cleavage; however, the strength of the 10Ni5CrMo steel did not change significantly. The hydrogen embrittlement coefficient reached a threshold of $25 \%$, while the polarization potential was approximately $-992 \mathrm{mv}$ (vs. SCE). In conclusion, the limiting cathodic protection potential of $10 \mathrm{Ni}$ CrMo steel in a seawater environment was $-992 \mathrm{mv}$.
\end{abstract}

Keywords: 10Ni5CrMo steel, cathodic polarization, hydrogen embrittlement, high strength steel, SSRT

\section{$\underline{\text { FULL TEXT }}$}

(C) 2019 The Authors. Published by ESG (www.electrochemsci.org). This article is an open access article distributed under the terms and conditions of the Creative Commons Attribution license (http://creativecommons.org/licenses/by/4.0/). 